\title{
ETNOECOLOGIA E EDUCAÇÃO AMBIENTAL SOBRE MANGUEZAIS COM INDÍGENAS
}

\author{
Geovani Oliveira ${ }^{1}$ \\ Lídia Nogueira de Queiroz ${ }^{2}$ \\ Rafaela Camargo Maia ${ }^{3}$
}

Resumo: Tendo em vista a grande importância dos saberes populares, faz-se necessário o diagnóstico dos conhecimentos etnoecológicos da população indígena no distrito de Almofala (CE), sobre o manguezal, umas das áreas mais utilizadas pela tribo. Neste sentido, o objetivo geral deste trabalho é implementar ações visando o equilíbrio ambiental das áreas indígenas por meio de pesquisa aplicada etnoecológica, valorização do conhecimento local, formação de educadores ambientais e fortalecimento das organizações locais, possibilitando a sustentabilidade da população. Através deste estudo concluise, que é necessária a continuação de campanhas e projetos de Educação Ambiental para a comunidade indígena Tremembé acerca dos manguezais.

Palavras-chave:Comunidades Tradicionais; Mangue; Meio Ambiente.

Abstract: In view of the great importance of popular knowledge, it is necessary to diagnose the ethno-ecological knowledge of the indigenous population in the district of Almofala (CE, Brazil), about the mangrove one of the areas most used by the indian tribe. In this sense, the general objective of this work is to implement actions aimed at the environmental balance of indigenous areas through applied ethnoecological research, valuing local knowledge, training environmental educators and strengthening local organizations, enabling the sustainability of the population. Through this study, it is concluded that it is necessary to continue environmental education campaigns and projects for the Tremembé indigenous community about mangroves.

Keywords: Traditional Communities; Mangrove; Environment.

1'Instituto Federal do Ceará. E-mail: geovania.o@hotmail.com Link para o Lattes: http://lattes.cnpq.br/3663430047154512

2Instituto Federal do Ceará. E-mail: lidia10.queiroz@gmail.com Link para o Lattes: http://lattes.cnpq.br/8403747569643499

${ }^{3}$ Instituto Federal do Ceará. E-mail: rafaelamaia@ifce.edu.br. Link para o Lattes: http://lattes.cnpq.br/9316001630165818 


\section{Introdução}

O manguezal é um ecossistema costeiro que ocorre em terrenos baixos, sujeitos à ação das marés, formado por solos lodosos ou arenosos, com influência fluviomarinha, os quais se associa, predominantemente, a vegetação natural conhecida como mangue (BRASIL, 2012). Ocupa uma fração significativa do litoral brasileiro, desempenhando diversas funções naturais de grande importância ecológica e econômica. Destaca-se a sustentação da cadeia trófica costeira, por ser fonte de detritos para águas adjacentes, e serve como área de refúgio, alimentação e reprodução para muitas espécies animais (LEE et al., 2014). Produz bens e serviços para sociedade, representando a principal fonte de renda e subsistência para inúmeras comunidades pesqueiras tradicionais, destacando-se o extrativismo de macroinvertebrados bentônicos (REZENDE et al., 2015).

Entretanto, a intensa utilização de recursos naturais ameaça a existência do ecossistema manguezal, principalmente porque muitas regiões litorâneas se tornaram grandes centros populacionais e econômicos (FERREIRA; LACERDA, 2016). Dessa forma, ações sustentáveis são necessárias para que a comunidade continue aproveitando de forma harmônica - ecossistema manguezal. Entretanto, a falta de conhecimento sobre a importância desse ecossistema é uma das maiores dificuldades para sua conservação e por esse motivo, várias ações de Educação Ambiental têm sido realizadas a fim de sensibilizar as populações para a problemática, especialmente no ambiente escolar.

Nesse contexto, pode-se destacar algumas pesquisas que já foram desenvolvidas em escolas com o objetivo de diminuir os impactos causados pelo o homem ao ecossistema manguezal. Farrapeira, Silva e Lima (2007) observaram que as comunidades estudantis de Recife detinham um conhecimento relativo sobre o manguezal, possivelmente por viver nas proximidades dele. Farias e Andrade (2010) realizaram um estudo sobre manguezal que margeia o Rio Sergipe, em Aracaju (SE). Foi, esse trabalho foi desenvolvido em duas escolas por meios de visualizações fotográficas, questionários e discussões sobre o tema. E ainda, o trabalho de Albuquerque $\mathrm{e}$ Maia (2018), em Acaraú (CE), com a produção de cartilhas educativas para o ensino fundamental. No entanto, há uma escassez de trabalhos realizados com indígenas sobre o ecossistema manguezal.

$\mathrm{Na}$ educação contemporânea, os saberes populares de grupos indígenas e comunidades tradicionais sobre a natureza têm sido valorizados, utilizando-se do conhecimento comum ou etnoecologia para preservação de ecossistemas (ARÁN, 2019; CAPITANGO; CALLEJAS, 2019). Alves, Tomasi e Sahr (2011) mostram a competência de comunidades tradicionais em várias áreas do conhecimento, como etnociência na reconstrução agropecuária, a etnobotânica na reconstrução florística e os conhecimentos etnofaunísticos. Reconhecem-se esses saberes e as formas de manejo a eles pertinentes como fundamentais na preservação do meio ambiente, incluindo o ecossistema

Revista brasileira educação ambiental 
manguezal (ALBUQUERQUE; FARIAS; MAIA, 2016). Entretanto, muito desse conhecimento vem se perdendo com o tempo.

Veríssimo et al. (2003) relatam que com o processo de ocupação dos territórios cearenses, os povos indígenas eram escravizados ou expulsos de seus locais de origem, restando poucos remanescentes no Ceará, entre eles, destacam-se os Tremembés. Esses, mesmo com toda a dificuldade, ainda conseguiram manter sua tradição, e atualmente, então localizados em Itarema, Acaraú, Itapipoca e Fortaleza (ARAUJO; RIBEIRO; LIMA, 2018; LIMA et al., 2018). Nesse contexto, surge a escola indígena Tremembé, que segundo Veríssimo et al. (2003), busca além do processo de ensino-aprendizagem, uma maior compreensão da realidade local.

Tendo em vista a grande importância dos saberes populares como contribuintes aliados aos conhecimentos científicos e à escassez de pesquisas desenvolvidas neste âmbito, faz-se necessário 0 diagnóstico dos conhecimentos etnoecológicos da população indígena Tremembé, especialmente sobre o manguezal, um dos ecossistemas mais utilizados pela tribo para sua subsistência no Ceará.

Nesse sentido, o presente trabalho tem como objetivo geral, implementar ações visando o equilíbrio ambiental das áreas indígenas por meio de pesquisa aplicada etnoecológica, valorização do conhecimento, formação de educadores ambientais e fortalecimento das organizações locais possibilitando a sustentabilidade da população. E, especificamente: i) analisar o conhecimento empírico de estudantes da escola indígena e de indígenas mais idosos na tribo de Almofala-CE sobre o ecossistema manguezal e; ii) Propor uma intervenção ambiental para o público indígena para aprimorar o conhecimento dos alunos e professores da escola indígena sobre o ecossistema manguezal.

\section{Material e métodos}

\section{Área de estudo}

O presente trabalho foi desenvolvido no distrito de Almofala (CE), área costeira município de Itarema, cerca de $198 \mathrm{~km}$ de Fortaleza, capital do estado do Ceará, especificamente na Escola Indígena Tremembé Maria Venância. A Escola Indígena Tremembé é uma escola diferenciada com apenas uma turma do ensino médio, dividindo-se em quatro categorias: Inicial, Intermediário, Avançado I e Avançado II. As aulas presenciais só ocorrem uma semana por mês, com a conclusão do ensino médio em cinco anos.

Nessa região, ocorre a ocupação dos manguezais por empresas que exploram em escala industrial os recursos naturais, a invasão de áreas por posseiros e a implantação de fazendas de camarão que causaram o desmatamento do mangue, a impermeabilização do solo e contaminação dos recursos hídricos (MAIA, 2016; THIERS; MEIRELES; SANTOS, 2016) tradicionalmente utilizados pelos indígenas. 


\section{Metodologia}

O presente trabalho foi desenvolvido no período entre 2013 e 2017. Durante esses anos de pesquisa houve a participação de 129 estudantes indígenas. O público-alvo tinha faixa etária entre 14 e 36 anos.

Para a realização desta pesquisa foram utilizadas observações em sala de aula, aplicações de questionário, entrevista com o público não estudantil, oficinas de produção de mudas, reflorestamento de uma área de manguezal degradada e palestra de sensibilização a respeito do ecossistema manguezal. Foram realizadas as seguintes etapas: diagnóstico, resposta para a comunidade e Educação Ambiental.

\section{Diagnóstico}

Inicialmente foi feita uma solicitação ao Cacique da tribo a fim de iniciar a pesquisa no ano de 2013. Após o aceite do Cacique foi aplicado um questionário para conhecer a percepção dos alunos da escola indígena. $O$ mesmo tinha sete perguntas, sendo seis abertas e uma discursiva, relacionadas ao ecossistema manguezal. Os alunos tiveram o tempo de 20 minutos para a resolução, após esse tempo os questionários foram recolhidos e levados para o Laboratório de Ecologia de Manguezais (ECOMANGUE) para análise. O questionário serviu para analisar a percepção dos estudantes indígenas a respeito do ecossistema manguezal referente ao conceito, à importância, à flora e fauna típicas do ecossistema, além de um relato da experiência pessoal com esse ambiente.

A fim de sondar o conhecimento do público não estudantil foram realizadas entrevistas filmadas sobre o ecossistema manguezal com moradores da comunidade. Essa entrevista foi realizada com as pessoas mais idosas da aldeia, pessoas que acompanharam a evolução do manguezal da comunidade desde jovens até os dias de hoje. A entrevista deu-se da seguinte forma: os entrevistados foram questionados de como eram os manguezais da região da aldeia no período de sua juventude, e como se encontram nos dias atuais. A seguir, os entrevistados falavam tudo que lembravam, sem interrupções e por tempo indeterminado.

\section{Resposta para a comunidade}

Em 2014, ao término do primeiro momento de aplicação de questionário e entrevistas, os resultados obtidos foram apresentados de forma expositiva e dialogada para a comunidade em forma de banner. 


\section{Educação Ambiental}

Os resultados obtidos no diagnóstico serviram de subsídios para elaboração da proposta de intervenção de Educação Ambiental para comunidade indígena estudada. Assim, para promover a Educação Ambiental para o ecossistema manguezal junto aos Tremembés foram realizadas as seguintes ações: palestra, uma oficina para produção de mudas de mangue junto aos estudantes e comunidade em geral, além do reflorestamento de uma área a fim de contribuir com a restauração desse ecossistema na região.

\section{Análise de dados}

Para analisar os dados coletados nesta pesquisa nas fases de diagnóstico, foram utilizadas as metodologias propostas por Rodrigues e Farrapeira (2008), bem como de Vairo e Rezende-Filho (2010). Esses pesquisadores classificam as respostas obtidas nos seus questionários em três categorias: "Satisfatória", para as respostas completas nas quais os alunos demonstraram ter um conhecimento significativo do assunto; "Parcialmente Satisfatória", para aquelas que os alunos demonstraram ter um conhecimento mínimo a razoável (mas incompleto) do assunto abordado; e "Insatisfatórias", no caso dos alunos que demonstraram ou declararam nada saber sobre o assunto, ou ainda, quando os mesmos deixaram as questões em branco. Posteriormente, as respostas foram organizadas por meio de planilhas eletrônicas e gráficos; e, os relatos gravados dos indígenas mais idosos foram transcritos.

\section{Resultados}

\section{Diagnóstico discente}

No diagnóstico com os discentes indígenas, na questão 1 (Figura 1), que versava sobre a definição de manguezal, houve um percentual de $39 \%$ de respostas satisfatórias, nas quais os participantes sabiam definir o manguezal com duas ou mais características, explicar que o manguezal é um ecossistema, citar os animais que o habitam e sua vegetação diferenciada; $39 \%$ foram respostas parcialmente satisfatórias, ou seja, sabiam definir manguezal com um exemplo; e $22 \%$ foram consideradas insatisfatórias, já que não souberam responder. 


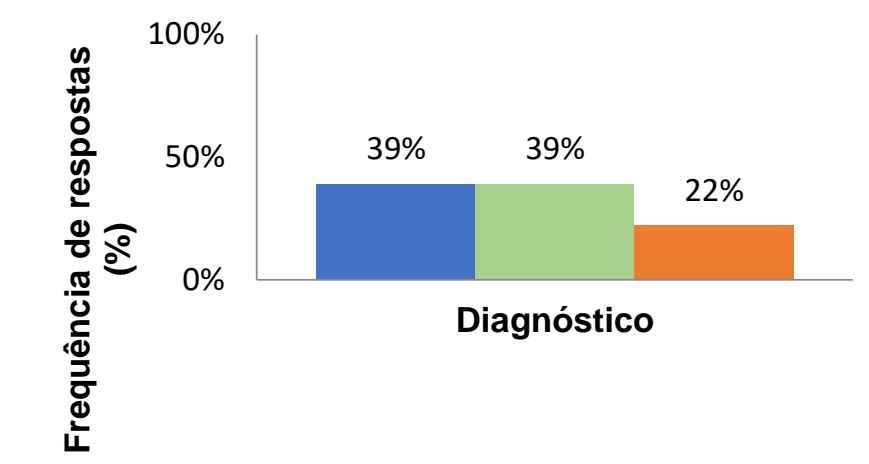

n Satisfatória = Parcialmente satisfatória natisfatória

Figura 1: Frequência de respostas (\%) dos alunos referente à questão 1: você sabe o que é um manguezal? Classificando-as quanto às categorias satisfatória, parcialmente satisfatória e insatisfatória, referente ao diagnóstico.

Fonte: Elaborada pelas autoras

$\mathrm{Na}$ questão 2 (Figura 2), sobre a importância do manguezal, os resultados obtidos inicialmente foram $61 \%$ de respostas satisfatórias uma vez que os alunos sabiam da importância do manguezal como fonte de renda e sua importância no equilíbrio ecológico; 39\% das respostas foram parcialmente satisfatórias indicando que sabiam da importância do ecossistema, apresentaram uma característica; e nenhum resultado foi considerado insatisfatório.

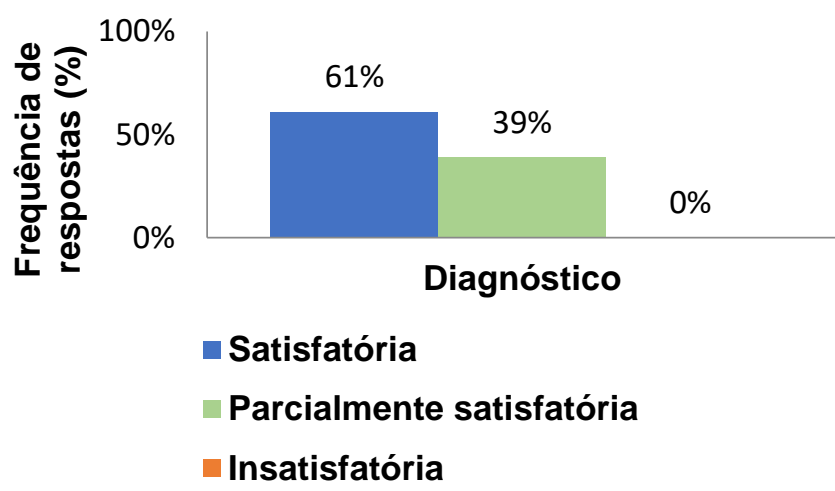

Figura 2: Frequência de respostas (\%) dos alunos referentes à questão 2: você acredita que o manguezal é importante? Por quê? Classificando-as quanto às categorias satisfatória, parcialmente satisfatória e insatisfatória, referente ao diagnóstico.

Fonte: elaborada pelas autoras

A questão 3 (Figura 3) sobre o conhecimento dos animais que habitam o manguezal teve como resultado $67 \%$ de respostas satisfatórias, nas quais os discentes sabiam quais animais vivem no manguezal, citando crustáceos, especialmente o siri azul, caranguejo uçá e o sié ou mão no olho e, alguns 
peixes. Foram parcialmente satisfatórias, $22 \%$ das respostas, considerando que sabiam dizer que animais vivem, mencionando um exemplo. E, $11 \%$, insatisfatórias, pois não sabiam dizer que animais vivem no manguezal ou citavam organismos de outros ecossistemas.

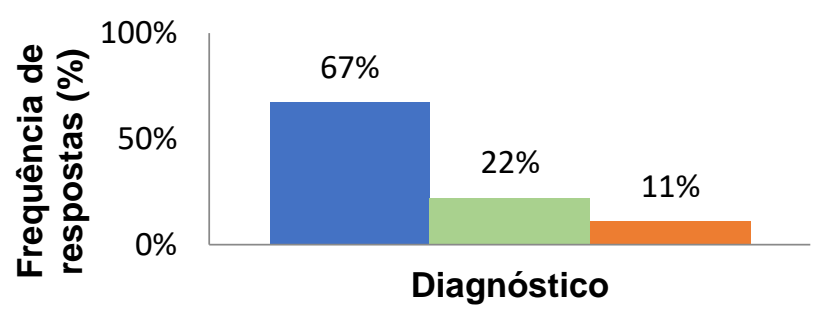

- Satisfatória

Parcialmente satisfatória

- Insatisfatória

Figura 3: Frequência de respostas (\%) dos alunos referentes à questão 3: quais animais vivem no manguezal? Você conhece algum? Descreva. Classificando-as quanto às categorias satisfatória, parcialmente satisfatória e insatisfatória, referente ao diagnóstico.

Fonte: elaborada pelas autoras

A questão 4 (Figura 4), referente ao conhecimento da flora do manguezal apresenta os seguintes resultados no diagnóstico: $78 \%$ satisfatórias, uma vez que os discentes demonstraram conhecê-la, respondendo mangue vermelho, mangue preto ou mangue botão; $17 \%$, parcialmente satisfatórias, com apenas um desses exemplos; e, 5\%, insatisfatórias, não conheciam ou citaram plantas de outros ecossistemas.

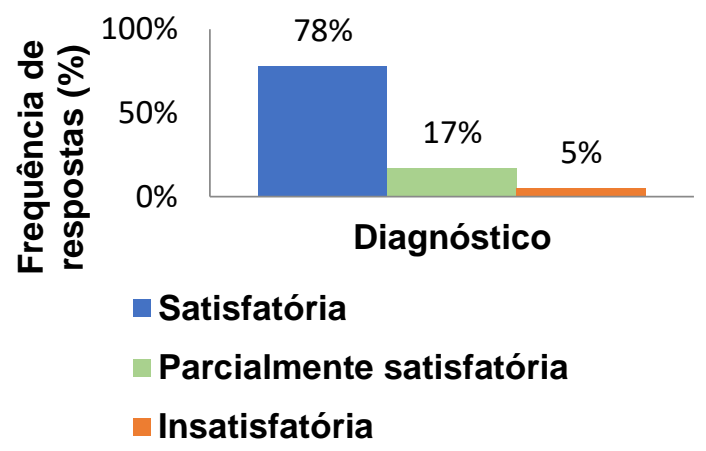

Figura 4: Frequência de respostas (\%) dos alunos referentes à questão 4: você conhece a flora do manguezal? Comente sobre ela. Classificando-as quanto às categorias satisfatória, parcialmente satisfatória e insatisfatória, referente ao diagnóstico.

Fonte: elaborada pelas autoras 
alunos responderam que é necessário conservar o manguezal por ele fazer parte do ecossistema e manter o equilíbrio da natureza; $33 \%$ foram parcialmente satisfatórias, pois sabiam por que preservar o manguezal dando um exemplo; e nenhuma resposta foi insatisfatória.

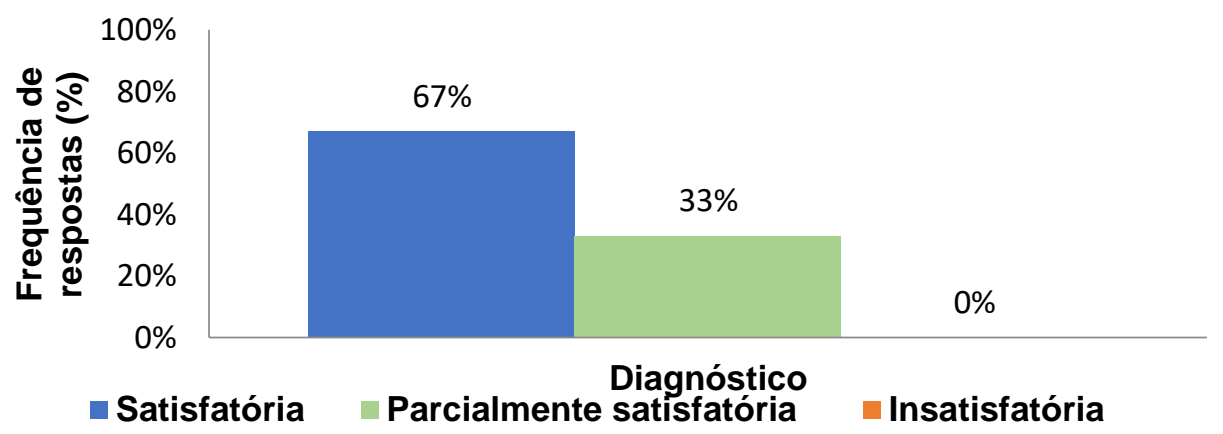

Figura 5: Frequência de respostas (\%) dos alunos referentes à questão 5: Por que preservar o manguezal? Classificando-as quanto às categorias satisfatória, parcialmente satisfatória e insatisfatória, referente ao questionário.

Fonte: elaborada pelas autoras

A questão 6 (Figura 6), referente às diferenças do manguezal para os demais ecossistemas, mostra que apesar dos indígenas apresentarem um conhecimento satisfatório sobre a importância do ecossistema manguezal, sua flora, fauna e conservação, os alunos indígenas pesquisados não conseguiram apontar as diferenças desse ecossistema para os demais. Apenas $5 \%$ foram respostas satisfatórias que indicavam que sabiam as diferenças entre o manguezal e os demais ecossistemas, mencionando que são alagadiços e que se adaptam a salinidade; $17 \%$ foram parcialmente satisfatórias uma vez que sabiam as diferenças entre manguezal e os demais ecossistemas e citaram um único exemplo; e, $78 \%$ foram insatisfatórias pois não sabiam a diferença entre manguezal e os demais ecossistemas.

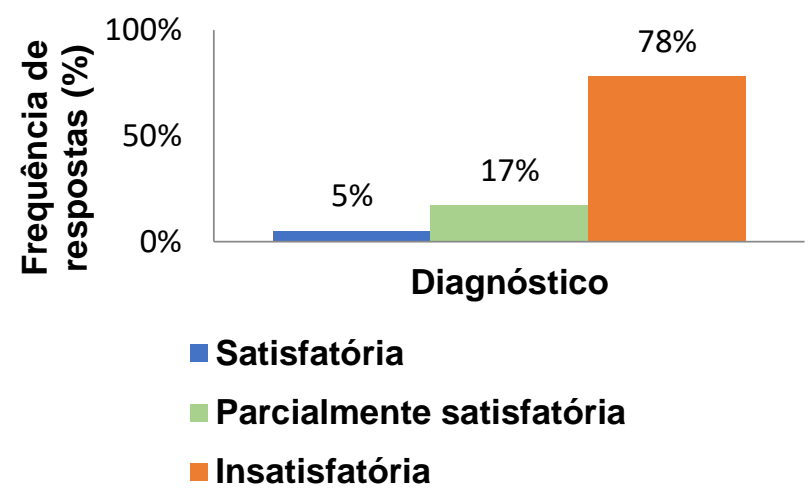

Figura 6: Frequência de respostas (\%) dos alunos referentes à questão 6: quais as diferenças do manguezal para os demais ecossistemas? Classificando-as quanto às categorias satisfatória, parcialmente satisfatória e insatisfatória, referente ao diagnóstico.

Fonte: elaborada pelas autoras. 
O objetivo da questão 7 (Figura 7) foi saber se os alunos já tiveram algum tipo de contato com o manguezal, seja por passeios oferecidos pela escola, seja por viagem, ou se já ouviram falar. Os resultados obtidos nessa questão tanto no diagnóstico inicial quanto final indicam que 100\% dos entrevistados conheceram o manguezal por meio de passeios oferecidos pela escola.

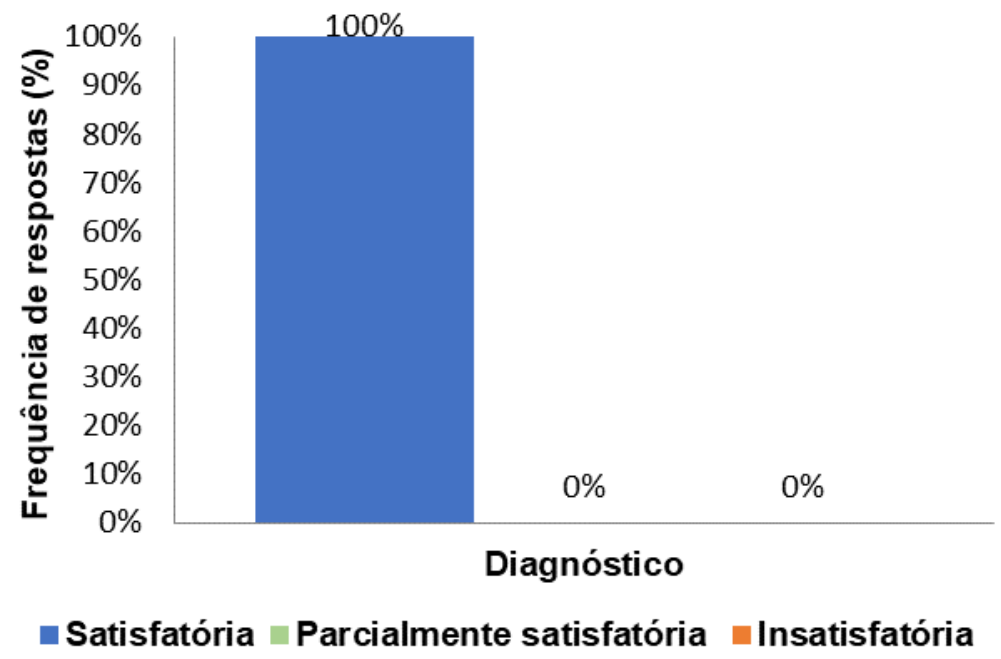

Figura 7: Frequência de respostas (\%) dos alunos referentes à questão 7: você já esteve em um manguezal? Classificando-as quanto às categorias satisfatória, parcialmente satisfatória e insatisfatória, referente ao diagnóstico.

Fonte: elaborada pelas autoras

\section{Diagnóstico dos moradores mais idosos da aldeia}

As entrevistas realizadas com os índios mais velhos da Aldeia de Almofala demonstram que os Tremembés consideram o manguezal como fonte de subsistência e fundamental para sua manutenção na região. Apresenta-se como ponto constante nas citações, a preocupação com os frequentes impactos sofridos pelo ecossistema, conforme se observa nos trechos retirados das entrevistas em vídeo, exemplos (1); (2) e (3):

(1) "A natureza a gente tem que respeitar, por que a natureza a Santa natureza. Ela que nos dá o que a gente precisa, em termo da alimentação de tudo. Principalmente do mangue, porque do mangue a gente tem uma grande fonte de renda para os povos indígenas, hoje não tem mais não, porque tão acabando com o mangue. Acabaram. Agora, assim a gente sabe respeitar, mais a outra população que não tem noção que hoje não tem dimensão da vida, vivem em outro setor, eles não tem essa dimensão que a gente tem pelo mangue." [sic] (J.V., 56 anos). 
(2) "O mangue umas florestas muito bonitas, umas coisas livres, umas coisas saudáveis, umas coisas fartas. Não tinha camboa, não era destruído, hoje em dia em dia tá tudo destruído o mangue. Acabaram tudo, o pessoal tira, faz o desmatamento, faz aí tudo isso vai ficando mais difícil." [sic] (M.B., 68 anos)

(3) "Os caranguejos não se perde, nos come tudo, tinha muita concha. Quando eu era criança nem ligava muito pra essas coisas, era muita fartura, só comecei a perceber quando tudo foi destruído. E hoje tudo aquela fartura acabou-se." [sic] (G.M.A., 84 Anos)

\section{Resposta à Comunidade}

Os resultados desse diagnóstico foram apresentados aos estudantes e professores da Escola Indígena Maria Venância, e para outros membros da comunidade indígena Tremembé. $\mathrm{Na}$ ocasião, os indígenas puderam refletir por meio de uma breve discussão, o quanto esse ecossistema é importante para o seu dia-dia e sua subsistência. Foram apresentados exemplos da sua fauna, flora e fragilidades, houve correção de erros apontados nas respostas do questionário.

O público-alvo do trabalho ficou muito animado em saber que suas respostas contribuíram para a pesquisa e pelo fato de ter sido levado um pouco do conhecimento Tremembé para outros locais. Após a apresentação, o banner foi doado a escola como forma de agradecimento, marcando o início do processo de intervenção ambiental na escola.

\section{Educação Ambiental}

Primeiramente, junto à comunidade estudantil e as pessoas que moram em volta do manguezal, foi realizada uma oficina sobre o ecossistema manguezal na qual foram abordados diversos assuntos dentre eles, o que é um ecossistema manguezal, importância, flora e fauna.

Foi observada ainda a importância do reflorestamento florestal do manguezal na área próxima a aldeia Tremembé, pelo relatado nas entrevistas e avaliado no diagnóstico de percepção ambiental. Assim, foi realizada uma oficina abordando como são feitas as mudas de mangue, período de rega e tempo adequado para replantio, seguindo os dados apresentados no trabalho de Paula, Lima e Maia (2016). Dessa forma, foram mostradas técnicas utilizadas para produzir as mudas de mangue vermelho (Rizophora mangle) ou mangue branco (Laguncularia racemosa), comuns na região (MAIA, 2016).

Ao todo, foram produzidas 305 mudas. Posteriormente, foi realizado o plantio das mudas no Mangue do Saquim apontado pela população como degradado (Figura 8).

Revista brasileira educação ambiental 

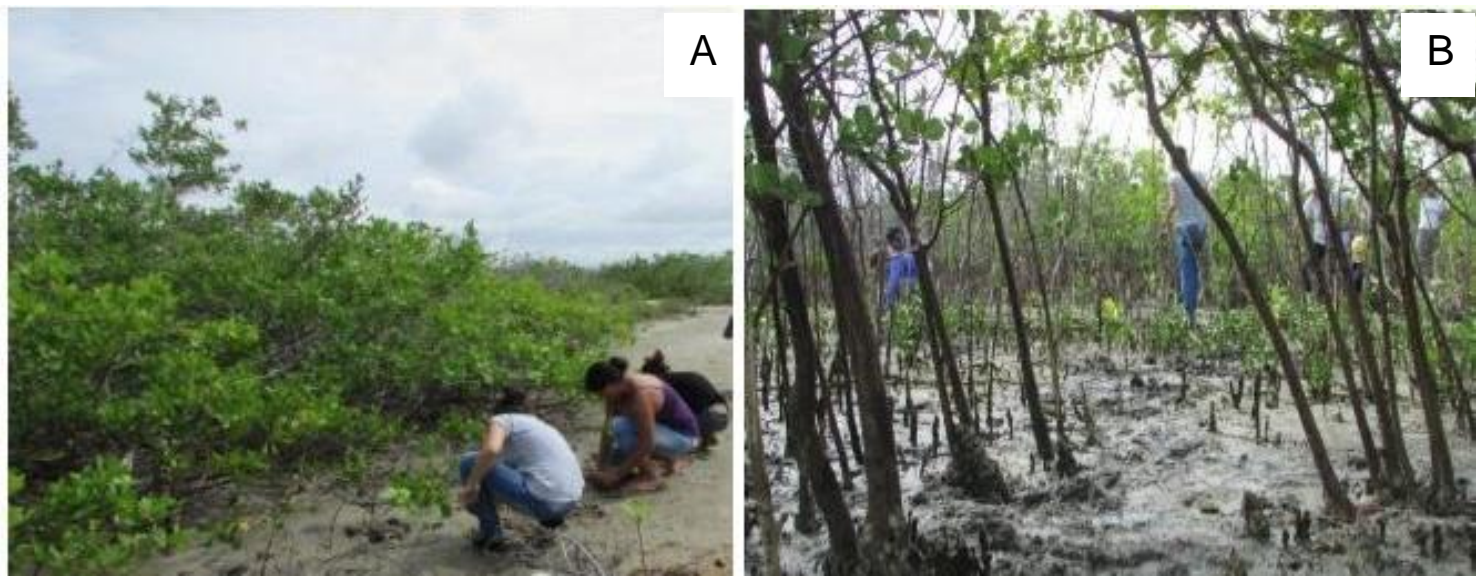

Figura 8: A- Estudantes indígenas fazendo o plantio das mudas; B- Estudantes indígenas observando o local após o plantio das mudas.

Fonte: Elaborada pelas autoras

Para promover a Educação Ambiental, ainda foi realizada uma palestra abordando diversos temas importantes sobre o ecossistema manguezal com os estudantes indígenas Tremembés (Figura 9). Foram os seguintes aspectos abordados: conceitos e princípios do ecossistema manguezal; distribuição dos manguezais em nível de mundo, Brasil e Ceará; flora; fauna; impactos ambientais; leis que protegem esses ecossistemas e por fim recuperações desses ambientes impactados.

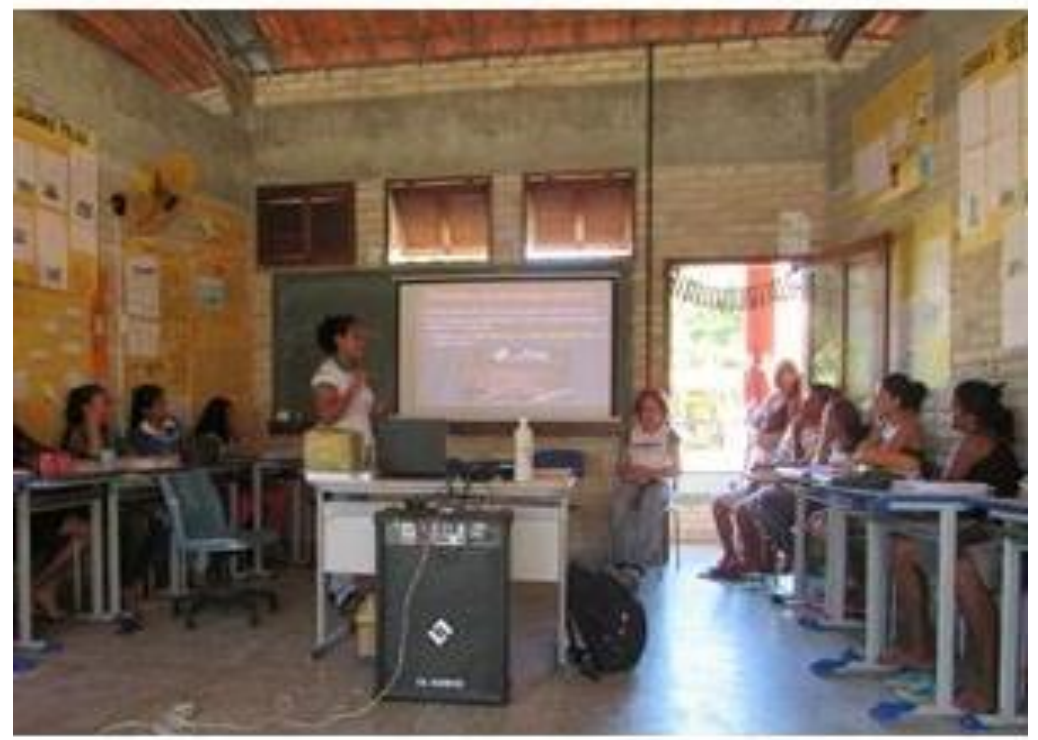

Figura 9: Palestra sobre Ecologia de Manguezais.

Fonte: Elaborada pelas autoras 


\section{Discussão}

Os dados obtidos para o diagnóstico realizado pelo presente trabalho, indicam que a escola estudada está trabalhando com clareza a temática. Os alunos têm total consciência das características do manguezal, sabendo sua importância tanto para equilíbrio ecológico como para sobrevivência do seu povo. Os estudantes em suas respostas ao questionário apresentam conhecimento de satisfatório a parcialmente satisfatório. Esse fato pode estar relacionado aos métodos utilizados em sala de aula, que envolvem os estudantes, já que é sempre realizado com uma aula teórica e uma aula de campo, o que faz com que eles fiquem mais próximos desses ambientes. Resultados semelhantes foram encontrados nos trabalhos de Pereira, Farrapeira e Pinto (2006) e Farrapeira, Silva e Lima (2007) com as comunidades estudantis do Recife que detinham um conhecimento relativo sobre o manguezal, possivelmente por viver nas proximidades dele, com contato com a fauna típica.

Os estudantes mostraram conhecimento satisfatório em relação à preservação dos manguezais, sempre relatando a importância para a sobrevivência de seu povo. Ao se referir aos animais que habitam o ecossistema as respostas foram sempre de satisfatória a parcialmente satisfatória. Comparando o conhecimento científico com o conhecimento popular em relação à fauna, Ucides cordatus, ou caranguejo uça, é a espécie mais comum de caranguejo em manguezais, Callinectes spp. é o siri azul, Uca spp. é o sié ou mão no olho. Caranguejos são os animais mais mencionados pelos alunos indígenas por ser um importante recurso alimentar e econômico para comunidades tradicionais. Pode-se observar a importância dos mesmos nos trabalhos de Pereira, Farrapeira e Pinto (2006), Rodrigues e Farrapeira (2008), Vairo e Rezende-Filho (2010) e Albuquerque, Farias e Maia (2016).

Entretanto, os estudantes demonstraram não saber que espécies de flora existem no manguezal e nem a diferença da vegetação de manguezal para os demais ecossistemas, um fato comum nos questionários. A espécie Conocarpus erectus é o mangue de botão, Avicennia sp. é mangue preto ou canoé, Laguncularia racemosa é o mangue branco e Rhizophora mangle, mangue vermelho (PAULA; LIMA; MAIA, 2016).

Os resultados também indicam que os indígenas mais idosos da aldeia, utilizavam o manguezal mais ativamente para busca de alimento para sua subsistência, tornando clara, em seus depoimentos, a sensação de estar nesse ecossistema. E mostraram preocupação com o manguezal, pois no decorrer dos anos vem sofrendo com o desmatamento e, por estarem com idade avançada, não se sentem capazes de fazer alguma ação no sentido de restaurar esses ambientes.

Souza et al. (2015) constataram que a valorização e o respeito dados pelos indígenas à natureza, representada nesse trabalho pelos manguezais, proporcionam-Ihes a sustentabilidade ambiental, difundida a partir de sua própria cultura. Para Diegues e Arruda (2001), um aspecto importante no

Revista brasileira educação ambiental 
conceito de cultura tradicional é o respeito aos ciclos da natureza e sua exploração sustentável. Tais características também são enfatizadas na Política Nacional de Desenvolvimento Sustentável de Povos e Comunidades Tradicionais do Brasil (BRASIL, 2007).

No entanto, o processo de urbanização tem forte influência sobre a maioria dos povos indígenas no Brasil, especialmente nos mais jovens da tribo (FARIAS; BARCELLOS, 2017). Essa nova geração, os alunos do ensino médio aqui avaliados, só entram em contato com esses ambientes por meio das atividades escolares. O distanciamento das relações sociais tradicionais e da estreita dependência do meio natural para subsistência pode levá-los a práticas que são claramente insustentáveis.

A promoção da palestra fez com que os estudantes conhecessem mais a fundo o ambiente onde estão inseridos, percebessem a importância do ecossistema, não apenas para o seu povo, mas para os próprios animais que habitam aqueles ambientes e os que passam parte de seu ciclo de vida. Os estudantes puderam ainda conhecer os nomes científicos da fauna e flora relacionandos ao conhecimento que eles já possuíam. Observaram ainda que o ecossistema manguezal tem uma ampla distribuição no mundo e não se limitava apenas a sua comunidade. Alves, Tomasi e Sahr (2011) utilizaram-se desse recurso em seu trabalho em 32 escolas públicas e particulares no Rio de Janeiro, tendo sucesso na recuperação de aproximadamente $2 / 3$ de áreas de manguezais daquela comunidade. Ações como essas são relevantes visto que a juventude indígena busca apoiar as demandas contemporâneas, como por exemplo, as ambientais, o que pode contribuir na preservação do ser e do viver ancestral (FARIAS; BARCELLOS, 2017).

A escola inteira foi envolvida nas ações de Educação Ambiental para o manguezal durante todo o tempo da intervenção. A Educação Ambiental em relação ao ecossistema manguezal procedeu de forma tão satisfatória na comunidade escolar que ao final do projeto, a escola encontrava-se com vários desenhos de manguezais. Concluindo assim, que toda a comunidade foi mobilizada e se tornou mais claro para os novos alunos a importância do ecossistema (Figura 10, próxima página), indicando o antes e depois da intervenção.

Espera-se que as metodologias utilizadas neste trabalho possam contribuir com a formação acadêmica desses estudantes. Estudos semelhantes ainda não foram realizados com indígenas e sua relação com o ecossistema manguezal para que resultados passíveis de generalizações possam ser alcançados. Por esse motivo, fazem-se necessárias novas abordagens sobre a temática, utilizando-se de outros recursos para uma melhor compreensão do assunto. 


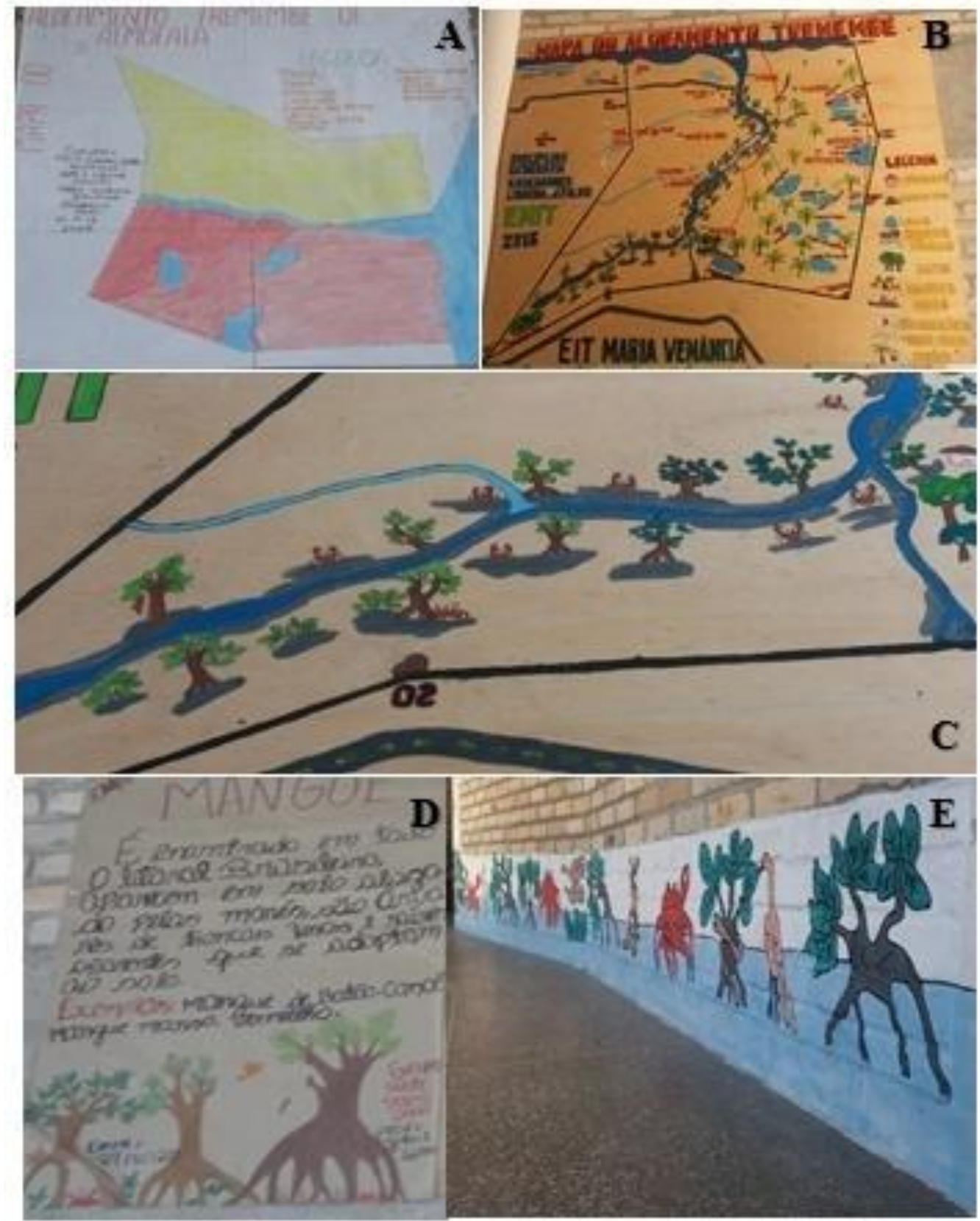

Figura 10: A- Desenho do mapa do Aldeamento Tremembé em 2013, no início da intervenção; B- desenho do mapa do Aldeamento Tremembé em 2017, ao final da intervenção, com a inclusão das áreas de manguezais; Cdestaque do manguezal no mapa do Aldeamento Tremembé em 2017; DCartazes com ilustrações sobre manguezais em 2013; E- Ilustrações nas paredes da escola indígena sobre manguezais em 2017.

Fonte: Elaborada pelas autoras 


\section{Conclusões}

Os resultados indicam que os estudantes indígenas apresentam, previamente, um conhecimento satisfatório a parcialmente satisfatório, o que está relacionado ao fato de terem sempre aulas teóricas seguidas de uma prática em ambientes adjacentes à tribo que apresentam manguezais.

Os indígenas mais idosos da aldeia mostraram-se bastante preocupados com o desmatamento dos manguezais, reconhecendo a importância dos recursos do mesmo para manutenção de seu povo, buscando assim envolver o máximo da comunidade nas atividades desenvolvidas nesta temática.

Diante dos resultados apontados neste trabalho, mesmo com resultados satisfatórios nos questionários, fez-se necessário ações de Educação Ambiental, principalmente para a nova geração de índios, que já não veem o manguezal com tanto admiração quanto os mais idosos, fazendo assim que haja uma maior intimidade dos mesmo com esses ambientes.

A promoção de palestras foi necessária para que os estudantes tivessem um conhecimento mais técnico de características, distribuição, nomes científicos e populares dos organismos de manguezais.

Conclui-se, portanto, que há a necessidade da continuação de campanhas e projetos de Educação Ambiental para a comunidade indígena Tremembé acerca do ecossistema manguezal, fazendo com que a comunidade fique mais próxima desse ecossistema, vendo-o como uma importante fonte de renda e subsistência, tendo consciência que esses recursos são limitados.

\section{Agradecimentos}

As autoras agradecem ao povo Tremembé, principalmente à comunidade acadêmica da Escola Indígena Maria Venância, pela disponibilidade, à Profa. Me. Maria do Socorro Cardoso de Abreu pela revisão linguística e ao Laboratório de Ecologia de Manguezais (ECOMANGUE) do Instituto Federal do Ceará, campus Acaraú, pelo suporte das atividades de campo.

\section{Referências}

ALBUQUERQUE, R.M.V.L; FARIAS, E.M.N; MAIA, R. C. Educação Ambiental para 0 Ecossistema Manguezal: $O$ papel dos pescadores artesanais. Conexões Ciência e Tecnologia, Ceará, v.9, n.4, p.1 -100, 2016. Disponível em: https://issuu.com/auzuirripardodealexandria/docs/pesca e aquicultura completa . Acesso em: 06 jul. 2016.

ALBUQUERQUE, R. M. V. L.; MAIA, R. C. Educa mangue: conhecendo o fascinante ecossistema manguezal. Acaraú: Ifce, 2018. Disponível em: https://ifce.edu.br/acarau/menu/EbookEducaMangue.pdf/view . Acesso em: 08 maio 2020. 
ALVES, A. P. A. F; TOMASI, T; SAHR, C. L. L. A Perspectiva Etnográfica na Identificação e Caracterização de Elementos Cotidianos de uma Comunidade Quilombola. Observatorium: Revista Eletrônica de Geografia, v.3, n.7, p.79-100, 2011.

ARÁN, R. R. Culturas marítimas na costa norte do México; natureza e cosmovisões em Altamar. Etnoecologia e nova etnografia. Revista de Educação Ambiental. Universidade Federal do Rio Grande - UFRG. Vol 24, n.2, 2019.

ARAÚJO, M. R.; RIBEIRO, S. S.; LIMA, M. C. W. Povo Tremembé e remanescentes de quilombo vivendo em Acaraú: histórias de luta por direitos e reconhecimento. 1. ed. Fortaleza: Pró-Reitoria de Extensão, 2018. v. 1. 85p .

BRASIL. Decreto $n^{\circ}$ 6.040, de 7 de fevereiro de 2007. Política Nacional de Desenvolvimento Sustentável de povos e Comunidades Tradicionais. Disponível em: http://www.planalto.gov.br/ccivil 03/ ato20072010/2007/decreto/d6040.htm. Acesso em 24 de janeiro de 2021.

BRASIL. Lei no $\mathbf{1 2 . 6 5 1}$ de 25 de maio de 2012. Estabelece o código florestal e dá outras providências. Diário Oficial da República Federativa do Brasil, Poder executivo, Brasília, DF,25 de maio. 2012.

CAPITANGO, J.; CALLEJAS, G. V. Conhecimentos, experiências e práticas vitais tradicionais indígenas como fundamento para a construção de uma cultura de sustentabilidade. Revista de Educação Ambiental. Universidade Federal do Rio Grande - FURG. Vol. 24, n.2, 2019.

DIEGUES, A. C.; ARRUDA, R. S. V. Saberes tradicionais e biodiversidade no Brasil. Brasília, DF: Ministério do Meio Ambiente; São Paulo: USP, 176 p., 2001.

FARRAPEIRA, C. M. R; SILVA, K.M. E; LIMA, A. O. Percepção e concepção do manguezal vinculados ao ensino da Biologia em uma escola de Recife-PE. Educação Ambiental em Ação, Novo Hamburgo, v 19, p. 1-9, 2007.

FARIAS, K. L; DE ANDRADE, R. C. B. Educação Ambiental: O manguezal no Ensino Fundamental. Revista Eletrônica do Mestrado de Educação Ambiental, v.25, 2010. ISSN 1517-1256.

FARIAS, E. S.; BACELLOS, L. A. Jovens Indígenas Tabajara: âncoras no processo de reivindicações na busca do bem viver no século XXI. Revista Tecnologia e Sociedade, v. 13, n. 29, p. 119-130, 2017.

FERREIRA, A. C.; LACERDA, Luiz D. 2016. Degradation and conservation of Brazilian mangroves, status and perspectives. Ocean and Coastal Management, n. 125, p. 38-46.

LEE, S. Y.; et al. Ecological role and services of tropical mangrove ecosystems: a reassessment. Global Ecology and Biogeography, Australian, v. 23, n. 7, p. 726-743, 2014. 
LIMA, M. C. W; et al. Índios Tremembé e remanescentes de quilombo vivendo em Acaraú: recontando histórias de luta por direitos e reconhecimento. Expressões da Extensão, v. 3, p. 25-31, 2018.

MAIA, R. C. Manguezais do Ceará. 1 ed. Recife: Imprima, 2016. 55 p.

PAULA, A. L. S.; LIMA, B. K. S.; MAIA, R. C. Recuperação de um manguezal degradado no Ceará através da produção de mudas de Laguncularia racemosa (L.) C.F. Gaertn. (Combretacea) e Avicennia sp. Stapf ex Ridl (Acanthacea). Revista árvore, Viçosa-MG, v.40, n.3, p.377-385, 2016.

PEREIRA, E.M.; FARRAPEIRA, C.M.R.; PINTO, S.L. Percepção e Educação Ambiental sobre manguezais em escolas públicas da Região Metropolitana do Recife. Revista Eletrônica do Mestrado em Educação Ambiental, Porto Alegre, v. 17, p. 244-261, 2006.

REZENDE, C. E. KAHN, J. R. PASSARELI, L. VÁSQUEZ, W. F. An economic valuation of mangrove restoration in Brazil. Ecological Economics. p. 296302, 120, 2015.

RODRIGUES, L. L.; FARRAPEIRA, C. M. R. Percepção e Educação Ambiental sobre o ecossistema manguezal incrementando as disciplinas de ciências e biologia em escola pública do Recife - PE. Revista Investigações em Ensino de Ciências, Porto Alegre, RS, v. 13, n. 1, 2008.

SOUZA, A. H. C.et al. A relação dos Indígenas com a natureza como contribuição à sustentabilidade ambiental: uma revisão da literatura. Revista Destaque Acadêmico, v. 7, n. 2, 2015.

THIERS, P. R. L; MEIRELES, A. J. A; SANTOS, J. O. Manguezais na costa oeste cearense: preservação permeada de meias verdades. Editora Imprensa Universitária, Fortaleza, 2016. p126.

VAIRO, A. C.; REZENDE-FILHO, L. A. R. Concepções de alunos do ensino fundamental sobre ecossistemas de manguezal: o caso de um colégio público do Rio de Janeiro.Ensino, Saúde e Ambiente, v. 3, n. 2, p. 15-25,

VERÍSSIMO, M. E. Z. et al. A Comunidade Tremembé: Cartilha de Educação Ambiental. Fortaleza, p. 5-9, 2003 